\title{
Applying the Method of Enhancing Feedback Control On a 4D Hyperchaotic System
}

\author{
Mahasin Thabit Younis \\ mahasinthabit@uomosul.edu.iq \\ College of Computer Sciences and Mathematics \\ University of Mosul, Mosul, Iraq
}

Received on: 02/09/2018

Accepted on: 24/01/2019

\section{ABSTRACT}

In this paper, we are using enhancing feedback control on a new continuous 4D autonomous hyper chaotic system proposed by Sadiq A. Mehdi and A. Hayder, Qasim [Analysis of a New Hyperchaotic System with six cross-product nonlinearities terms, 2017], this system has three critical points employs ten terms include six quadratic cross-product nonlinearity terms, We notice that when we apply any linear control method that relies on a single unit control added to the system, the system behavior in this case cannot control it, so we applied enhancing linear feedback control at origin and we noticed that a necessary condition for suppression is getting positive feedback coefficient. Theoretical analysis and numerical simulation check the validity of the results obtained.

Keywords: Dynamical Systems, Hyperchaotic System, Enhancing feedback control, Control Systems.

$$
\begin{aligned}
& \text { تطبيق طريقة سيطرة التغذية الخطية المحسنة على نظام رباعي كثير الاضطراب } \\
& \text { محاسن ثابت يونس } \\
& \text { كلية علوم الحاسوب والرياضيات } \\
& \text { جامعة الموصل، الدوصل، العراق }
\end{aligned}
$$

تاريخ قبول البحث: 2019/01/24

تاريخ استلام البحث: 2018/09/02

\section{الملخص}

تم في هذا البحث استخدام طريقة سيطرة التغذية الخطية المحنة على نظام جديد مستمر رباعي الأبعاد كثير الاضطراب المقترح من قبل Hayder A., Qasim و Sadiq A. Mehdi في عام 2017 يمتلك هذا النظام ثلاث نقاط حرجة، ويحتوي على عشرة حدود ستة منها غير خطية من الدرجة الثانية، ولوحظ انه عند تطبيق أي طريقة من طرق السيطرة الخطية التي تعتمد على إضافة عامل سيطرة وحيد الى النظام فان سلوك النظام في هذه الحالة لايمكن السيطرة عليه. باستثاء طريقة السيطرة الخطية المحسنة و استطعنا إيجاد مناطق استقرار هذا النظام عند نقطة الأصل، ولوحظ أن الشرط الضروري للقع هو الحصول على معامل تغذية موجب، التحليل النظري والمحاكاة العددية تحقق صحة النتائج التي حصلنا عليها. الكلمات المفتاحية: الانظمة الديناميكية، انظمة كثيرة الاضطراب، الطريقة المحسنة للتغذية الاسترجاعية، انظمة السيطرة.

\section{Introduction}

Henri Poincaré was the first scientist who discovered chaos in history in 1890, by answering the question posed by Weierstrass on the stability of the solar system, Poincaré discovered orbits for three or more than can depict of unstable and unpredictable of nonlinear dynamical systems. Poincare is the first person who discover a specific random system which led to the founding of what is now in chaos [10]. 
In 2017 Mehdi, S. A. and Qasim, H. A. [8] introduced a new hyperchaotic system the basic features of dynamical system, fractal dimension of system as 3.0243 , and system characteristics with high sensitivity and generate complex hyperchaotic attractor with two-scroll [8].

\section{System Description}

We introduce the new system as a new continuous 4D autonomous hyperchaotic system, the system contain ten terms include six quadratic cross-product nonlinear terms, this is the reason to make it hyperchaotic system. The new system has the form:

$\dot{f}=\left[\begin{array}{l}\dot{x}=a y z-b x z-c w \\ \dot{y}=d x-x z-y \\ \dot{z}=e x y-f z \\ \dot{w}=g x z+h z y\end{array}\right]$

where $x, y, z$, and $w$ are variable of the system and $a, b, c, d, e, f, g$ and $h$ are real constant parameters of system (1). When $a=18, b=3.1, c=2, d=10, e=3, f=2.6$,

$g=5$ and $h=13$. the system (1) is chaotic and belongs to the Lorenz system family [8]. The following figure described the attractors of this system [2].

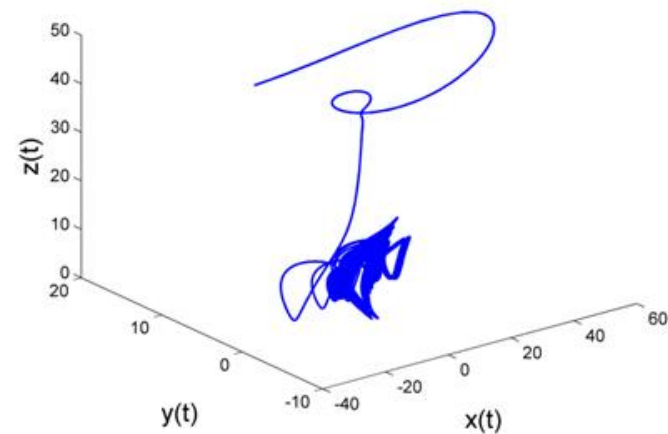

(a) $x-y-z$ space

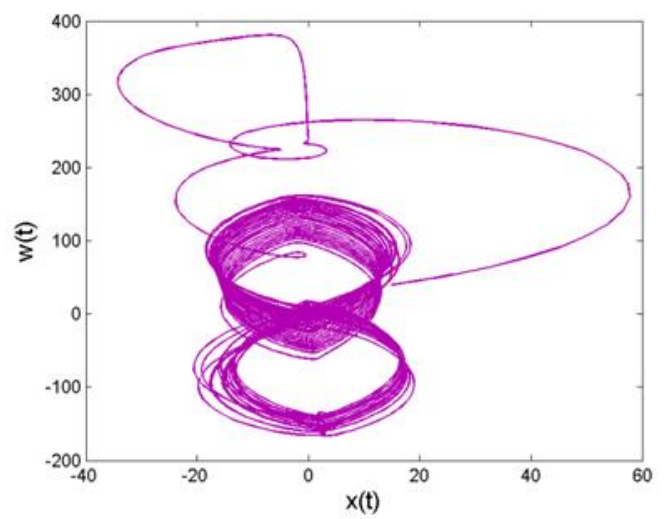

(c) $x-w$ plane

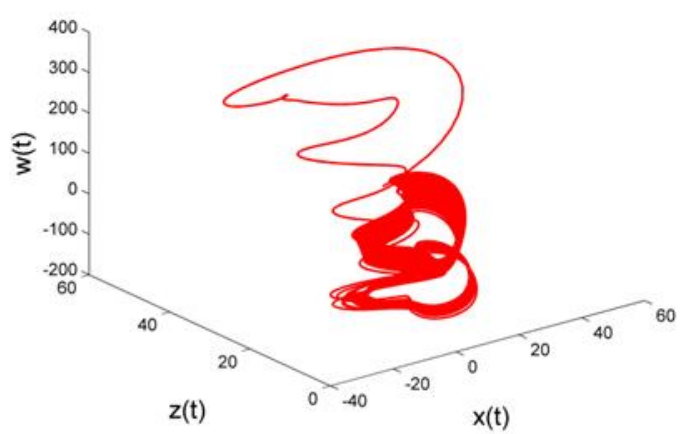

(b) $x-z-w$ space

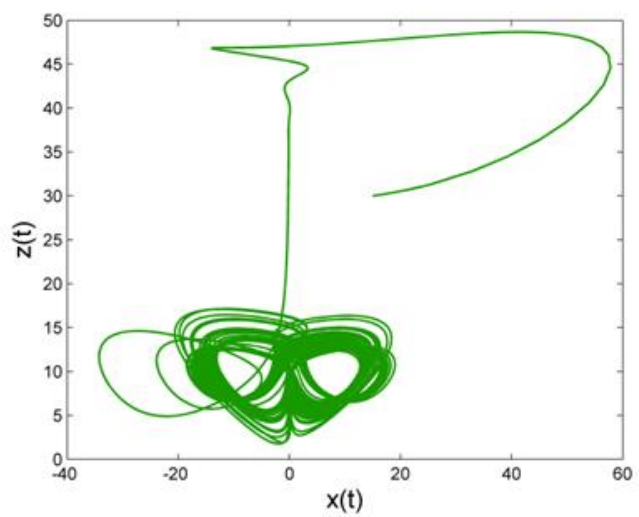

(d) $x-z$ plane

Figure (1): Attractor of the chaotic system

In system (1), when the coordinate is transformed from $(x, y, z, w)$ into $(-x,-y, z,-w)$, the new dynamical system is symmetry and invariant about the $z$-axis, and it is easily to see that the z-axis is invariant for the flow of the new hyperchaotic system and all orbits of the new system (1) starting from the z-axis stay in the z-axis for 
all values of time[2]. The equilibrium of the Eq. (1) have been found by solving four equations $\dot{x}=\dot{y}=\dot{z}=\dot{w}=0$, then we get

$$
P_{1}=\left[\begin{array}{l}
0 \\
0 \\
0 \\
0
\end{array}\right], \quad P_{2}=\left[\begin{array}{c}
0+4.8373 i \\
0-1.8605 i \\
10.8346 \\
0-251.7499 i
\end{array}\right], \quad P_{3}=\left[\begin{array}{c}
0-4.8373 i \\
0+1.8605 i \\
10.8346 \\
0-251.7499 i
\end{array}\right]
$$

We note that all equilibrium points are unstable. Therefore we have studied stabilization of this system at origin point $P_{1}=(0,0,0,0)$, by using enhancing linear feedback control [8].

\section{Definition (1): Enhancing Feedback Control}

Assume that the chaotic system has the form:

$\dot{f}=A X+h(X)$

where

$X(t)=\left[x_{i}\right]^{T}=\left[x_{1}, x_{2}, \ldots, x_{n}\right]^{T} \in R^{n+1}, i=1,2, \ldots, n$.

$A=\left(a_{i j}\right)_{n \times n}$ is the matrix parameters and $h: R^{n} \rightarrow R^{n}$ is the nonlinear part of the system. If we add the unit control $N$ to the Eq. (2), then the system has the form:

$$
\dot{f}=A X+h(X)+N
$$

The purpose of the unit control to become the $\lim _{t \rightarrow \infty}\|X(t)\|=0$. We can present the unit control by the form:

$$
N=n_{i}=\left\{-k\left[x_{i}\right]_{i=1}^{n} ; i=j\right\}
$$

such that $\mathrm{k}$ is feedback parameters and $k \Varangle 0$. This method depends on Routh Hurwitz Criteria, to find the exact value of feedback parameter, the necessary and sufficient condition to satisfy chaotic control and the feedback parameter must be positive, sometimes we get more than positive feedback parameter, to select good feedback parameter we must use the equation [4]:

$$
k=\bigcap_{i=1}^{n} k_{i}=k_{1} \cap k_{2} \cap \ldots \cap k_{n}
$$

In the method of enhancing feedback control we multiply system variables by more than one of the unit control and add to unstable chaotic system provided that equivalents the corresponding to the added variable [4].

4. Routh-Hurwitz Theorem (R. H. T.): Given the polynomial

$$
P(\lambda)=\lambda^{n}+c_{1} \lambda^{n-1}+\ldots+c_{n-1} \lambda+c_{n} .
$$

where the coefficients $c_{i}, i=1, \ldots, n$ are real constants, define the Hurwitz matrices using the coefficients $c_{i}$ of the characteristic polynomial:

$$
H_{1}=\left(c_{1}\right), \quad H_{2}=\left(\begin{array}{cc}
c_{1} & 1 \\
c_{3} & c_{2}
\end{array}\right), H_{3}=\left(\begin{array}{ccc}
c_{1} & 1 & 0 \\
c_{3} & c_{2} & c_{1} \\
c_{5} & c_{4} & c_{3}
\end{array}\right)
$$

When $n=4$, Routh-Hurwitz Criterion is defined as the form [1]:
1) $c_{1}>0$
2) $c_{1} c_{2}-c_{3}>0$ 
3) $c_{4}>0$

4) $c_{1} c_{2} c_{3}>c_{3}^{2}+c_{1}^{2} c_{4}$

We can find the Jacobian matrix of the system (1) as follows [8]:

$$
J=\left[\begin{array}{lllr}
-b z & a z a y-b x & -c \\
d-z & -1 & -x & 0 \\
e y & e x & -f & 0 \\
g z & h z & g x+h y & 0
\end{array}\right]
$$

The characteristic equation found by using $\operatorname{det}(J-\lambda I)=0$.

$$
\begin{aligned}
& \left|J P_{1}-\lambda I\right|=\left|\begin{array}{cccr}
-\lambda & 0 & 0 & -c \\
d & -1-\lambda & 0 & 0 \\
0 & 0 & -f-\lambda & 0 \\
0 & 0 & 0 & -\lambda
\end{array}\right|=0 \\
& \left|J P_{1}-\lambda I\right|=\lambda(-1-\lambda)(-f-\lambda) \lambda
\end{aligned}
$$

If we substitute $P_{1}$ and the value of real constant in the Eq. (6), the eigenvalues are: $\lambda_{1}=0, \lambda_{2}=-1, \lambda_{3}=-2.6$ and $\lambda_{4}=0$ [8]. By depending on the result of eigenvalues we notice that never use any one methods of linear feedback control on a chaotic system (1), because all these strategies (ordinary feedback control, dislocate feedback control and speed feedback control ) depend on adding one unit control on chaotic system remedy stable. But in strategy of enhancing linear feedback control we will add two or more unit control on the system (1).

Theorem (1) : The system (1) with control $N=\left[\begin{array}{llll}n_{1} & 0 & 0 & n_{4}\end{array}\right]^{T}$, where $n_{1}=-k x$ and $n_{4}=-k w$, the system (1) converge to the unstable equilibrium $P_{1}$ when $k \in(0, \infty)$.

Proof : The system(1) with new control can be written as :

$$
\left[\begin{array}{c}
\dot{x} \\
\dot{y} \\
\dot{z} \\
\dot{w}
\end{array}\right]=\left[\begin{array}{cccc}
-b z & a z a y-b x & -c \\
d-z & -1 & -x & 0 \\
e y & e x & -f & 0 \\
g z & h z g x+h y & 0
\end{array}\right]+\left[\begin{array}{c}
-k x \\
0 \\
0 \\
-k w
\end{array}\right]
$$

If we substitute $P_{1}$ and the values of real constants in the Eq. (8) we get the characteristic Eq. ;

$$
\lambda^{4}+c_{1} \lambda^{3}+c_{2} \lambda^{2}+c_{3} \lambda+c_{4}=0
$$

where $c_{1}=(3.6+2 k), \quad c_{2}=\left(2.6+7.2 k+k^{2}\right), c_{3}=\left(5.2 k+3.6 k^{2}\right)$ and $c_{4}=$ $2.6 k^{2}$

Now, according to the R. H.T. the Eq.(9) has four eigenvalues, all of them is real part and positive satisfied the condition in the Eq. (6).

Obviously, $\quad c_{1}=(3.6+2 k)>0, c_{1} c_{2}-c_{3}=\left(12.96 k+7.2 k^{2}+k^{3}\right)>0, c_{4}=$ $\left(2.6 k^{2}\right)>0$, we have a positive feedback coefficient $k>0$. Lastly, from the forth condition, we get;

$$
7.2 k^{5}+51.84 k^{4}+130.752 k^{3}+134.784 k^{2}+48.672 k>0
$$

If we solve the inequality of the Eq.(10) we get positive feedback coefficient $k>$ 0 , so that the active feedback control when $k>0$, as shown in Fig.2, we can take some values of $k$ and substitute these values in the Eq. (9) are given in Table 1. 
Table (1):List of eigenvalues corresponding to the characteristic Eq. (9) for different value of $\mathrm{k}$

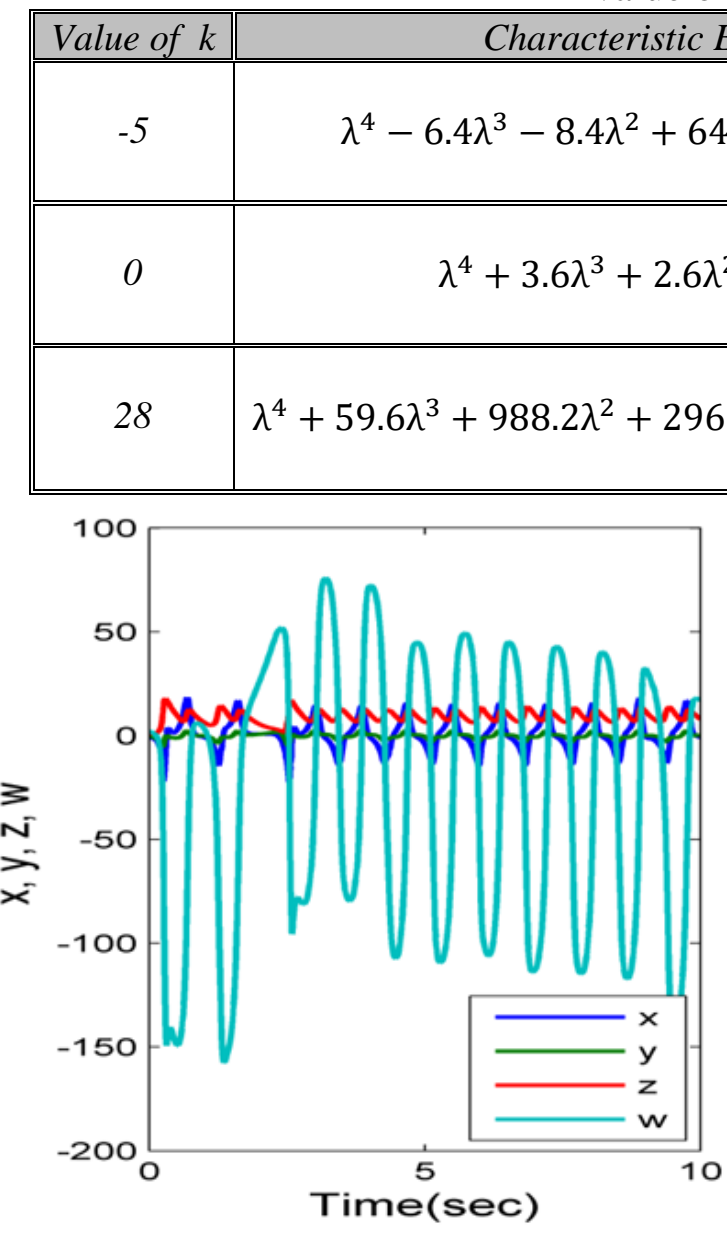

(a) : Chaotic system

Figure (2): Stabilization of system.

This method achieves the control of the system (1), because it satisfies all four conditions of $\quad$ R. H. T. and all the eigenvalues that have been obtained negative. The proof is complete.

Theorem (2): This theorem consisted of two parts : The system (1) with control $N=\left[\begin{array}{lll}n_{1} n_{2} & 0 & n_{4}\end{array}\right]^{T}$, where $n_{1}=-k x, n_{2}=-k y$ and $n_{4}=-k$ or $N=\left[\begin{array}{lll}n_{1} & 0 & n_{3} n_{4}\end{array}\right]^{T}, n_{1}=-k x, n_{3}=-k z$ and $n_{4}=-k w$, the system (1) converge to the unstable equilibrium $P_{1}$ when $k \in(0, \infty)$.

Proof part A: The system(1) with new control can be written as :

$$
\left[\begin{array}{c}
\dot{x} \\
\dot{y} \\
\dot{z} \\
\dot{W}
\end{array}\right]=\left[\begin{array}{cccr}
-b z & a z a y-b x & -c \\
d-z & -1 & -x & 0 \\
e y & e x & -f & 0 \\
g z & h z g x+h y & 0
\end{array}\right]+\left[\begin{array}{l}
-k x \\
-k y \\
0 \\
-k w
\end{array}\right]
$$

Then the characteristic Eq. is ;

$$
\lambda^{4}+c_{1} \lambda^{3}+c_{2} \lambda^{2}+c_{3} \lambda+c_{4}=0
$$

where $c_{1}=(3.6+3 k), c_{2}=\left(2.6+9.8 k+3 k^{2}\right), c_{3}=\left(5.2 k+8.8 k^{2}+k^{3}\right)$ and $c_{4}=2.6\left(k^{2}+k^{3}\right)$ 
Now, according to the R. H. T. the Eq. (11) has four eigenvalues all of them is real part and positive satisfied the condition in the Eq. (6).

Obviously, $\quad c_{1}=(3.6+3 k)>0, c_{1} c_{2}-c_{3}=\left(17.16+62.08 k+k^{2}+18.8 k^{3}+\right.$ $\left.3 k^{4}\right)>0$

and $c_{4}=2.6\left(k^{2}+k^{3}\right)>0$ we have a positive feedback coefficient $k>0$. Lastly, from the forth condition we get:

$$
8 k^{6}+78.4 k^{5}+276.24 k^{4}+416.128 k^{3}+245.648 k^{2}+48.672 k>0
$$

If we solve the inequality of the Eq. (12) we get a positive feedback coefficient $k>0$, so that the active feedback control when $k>0$. We can take some values of $\mathrm{k}$ and substitute these values in the Eq. (12) are given in Table 2:

Proof part B : The system(1) with new control can be written as :

$$
\left[\begin{array}{c}
\dot{x} \\
\dot{y} \\
\dot{z} \\
\dot{W}
\end{array}\right]=\left[\begin{array}{cccc}
-b z & a z a y-b x & -c \\
d-z & -1 & -x & 0 \\
e y & e x & -f & 0 \\
g z & h z & g x+h y & 0
\end{array}\right]+\left[\begin{array}{c}
-k x \\
0 \\
-k z \\
-k w
\end{array}\right]
$$

Then the characteristic Eq. is ;

$$
\lambda^{4}+c_{1} \lambda^{3}+c_{2} \lambda^{2}+c_{3} \lambda+c_{4}=0
$$

where $c_{1}=(3.6+3 k), \quad c_{2}=\left(2.6+8.2 k+3 k^{2}\right), c_{3}=\left(5.2 k+5.6 k^{2}+k^{3}\right)$ and $c_{4}=\left(2.6 k^{2}+k^{3}\right)$

Now, according to the R. H. T. the Eq.(15) has four eigenvalues all of them is real part and positive satisfied the condition in the Eq. (6).

Obviously $c_{1}=(3.6+3 k)>0$,

$$
c_{1} c_{2}-c_{3}=\left(9.36+32.12 k+29.8 k^{2}+8 k^{3}\right)>0 \text { and }
$$

$c_{4}=\left(2.6 k^{2}+k^{3}\right)>0$, we have a positive feedback coefficient $k>$

0 . Lastly, from the forth condition we get:

$$
8 k^{6}+65.6 k^{5}+195.6 k^{4}+275.072 k^{3}+185.744 k^{2}+48.672 k>0
$$

If we solve the inequality of the Eq.(16) we get a positive feedback coefficient

\begin{tabular}{|c|c|c|c|}
\hline 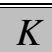 & & Characteristic Eq. & Eigenvalues \\
\hline \multirow[b]{2}{*}{-7} & Part A & $\lambda^{4}-17.4 \lambda^{3}+81 \lambda^{2}+51.8 \lambda-764.4=0$ & $\begin{array}{l}\lambda_{1}=-2.6 \\
\lambda_{2}=6 \\
\lambda_{3,4}=7 \pm 2.2302 \times 10^{-7}\end{array}$ \\
\hline & Part $B$ & $\lambda^{4}-17.4 \lambda^{3}+92.2 \lambda^{2}-105 \lambda-215.6=0$ & $\begin{array}{l}\lambda_{1}=-1 \\
\lambda_{2}=4.4 \\
\lambda_{3,4}=7 \\
\end{array}$ \\
\hline & Part A & $\lambda^{4}+27.6 \lambda^{3}+273 \lambda^{2}+1116.8 \lambda+1497.6=0$ & $\begin{array}{l}\lambda_{1}=-9 \\
\lambda_{2}=-2.6 \\
\lambda_{3,4}=-8 \pm 2.92002 \times 10^{-7} i\end{array}$ \\
\hline
\end{tabular}
$k>0$, so that the active feedback control when $k>0$, as shown in Fig. 3, we can take some values of $k$ and substitute these values in the Eq. (15) are given in Table 2.

Table (2): List of eigenvalues corresponding to the characteristic Eq. (12) and Eq. (15) for different values of $\mathrm{k}$ 


\begin{tabular}{|l|l|l|l|}
\hline 8 & Part $B$ & $\lambda^{4}+27.6 \lambda^{3}+260.2 \lambda^{2}+912 \lambda+678.4=0$ & $\begin{array}{l}\lambda_{1}=-10.6 \\
\lambda_{2}=-1 \\
\end{array}$ \\
& & $\lambda_{3,4}=-8 \pm 2.79571 \times 10^{-7} \mathrm{i}$ \\
\hline
\end{tabular}

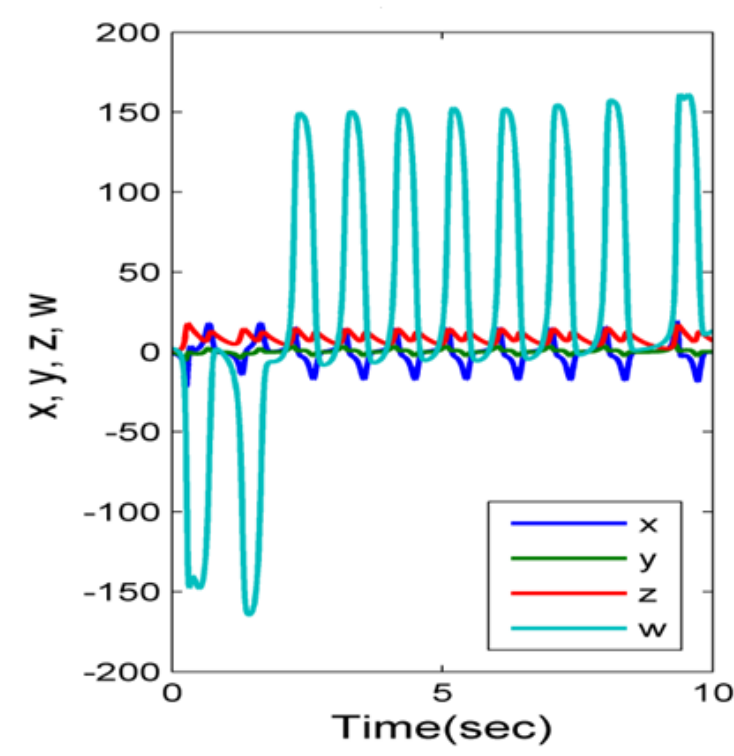

(a): Chaotic system

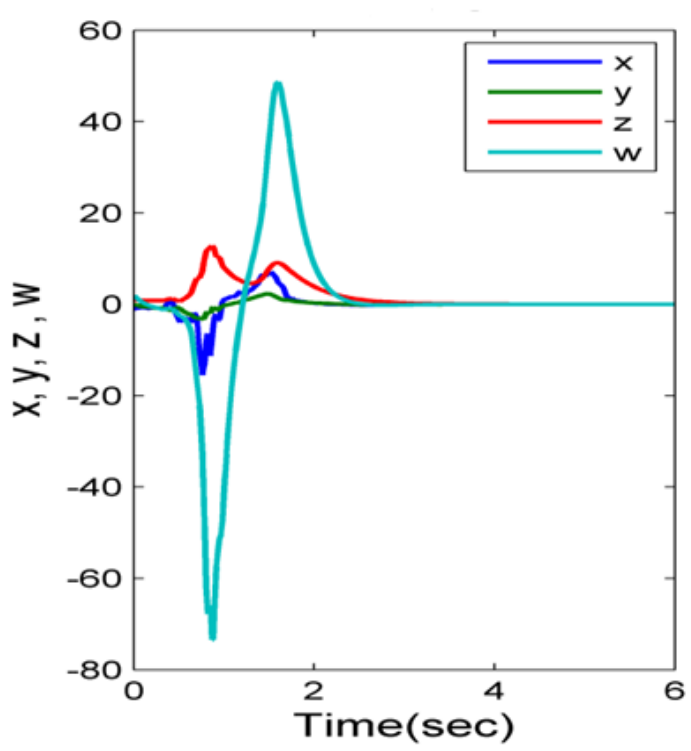

(b):After add unit control

Figure(3): Stabilization of system.

So that we controlled the behavior of the system and made it stable. The proof is complete.

Theorem (3): The system (1) with control $N=\left[\begin{array}{lll}n_{1} n_{2} & n_{3} n_{4}\end{array}\right]^{T}$ where $n_{1}=$ $-k x$ and $n_{2}=-k y, n_{3}=-k z$ and $n_{4}=-k w$, the system (1) converges to the unstable equilibrium $P_{1}$ when $k \in(0, \infty)$.

Proof: The system(1) with new control can be written as:

$$
\left[\begin{array}{l}
\dot{f}_{1} \\
\dot{f}_{2} \\
\dot{f}_{3} \\
\dot{f}_{4}
\end{array}\right]=\left[\begin{array}{cccr}
-b z & a z a y-b x & -c \\
d-z & -1 & -x & 0 \\
e y & e x & -f & 0 \\
g z & h z g x+h y & 0
\end{array}\right]+\left[\begin{array}{l}
-k x \\
-k y \\
-k z \\
-k w
\end{array}\right]
$$

Then the characteristic Eq. is ;

$$
\lambda^{4}+c_{1} \lambda^{3}+c_{2} \lambda^{2}+c_{3} \lambda+c_{4}=0
$$

where $c_{1}=(3.6+4 k), \quad c_{2}=\left(2.6+10.8 k+6 k^{2}\right), \quad c_{3}=\left(5.2 k+10.8 k^{2}+4 k^{3}\right)$ and $c_{4}=\left(2.6 k^{2}+3.6 k^{3}+k^{4}\right)$.

Now, according to the R. H. T. the Eq.(18) has four eigenvalues all of them is real part and positive satisfied the condition in the Eq. (6).

Obviously, $\quad c_{1}=(3.6+4 k)>0, c_{1} c_{2}-c_{3}=\left(9.36+44.08 k+54 . k^{2}+\right.$ $\left.20 k^{3}\right)>0$ and

$c_{4}=\left(2.6 k^{2}+3.6 k^{3}+k^{4}\right)>0$, we have a positive feedback coefficient $k>0$.

Lastly, from the forth condition we get:

$64 k^{6}+345.6 k^{5}+705.28 k^{4}+672.768 k^{3}+296.608 k^{2}+48.672 k>0$ 
If we solve the inequality of the Eq.(19) we get a positive feedback coefficient $k>0$, so that the active feedback control when $k>0$, as shown in Fig.4, we can take some values of $\mathrm{k}$ and substitute these values in the Eq. (18) are given in Table 3:

Table 3: List of eigenvalues corresponding to the characteristic Eq. (18) for different values of $\mathrm{k}$

\begin{tabular}{||c||c|l|}
\hline $\begin{array}{c}\text { Value of } \\
k\end{array}$ & \multicolumn{1}{|c|}{ Characteristic Eq. } & \multicolumn{1}{c|}{ Eigenvalues } \\
\hline \multirow{2}{*}{2} & $\lambda^{4}-4.4 \lambda^{3}+5 \lambda^{2}+0.8 \lambda-2.4=0$ & $\begin{array}{l}\lambda_{1}=-0.6 \\
\lambda_{2}=1 \\
\lambda_{3,4}=2\end{array}$ \\
\hline \hline \multirow{2}{*}{$\begin{array}{c}\lambda_{1}=-8.6 \\
\lambda_{2}=-7 \\
\lambda_{3,4}=-6\end{array}$} \\
\hline
\end{tabular}

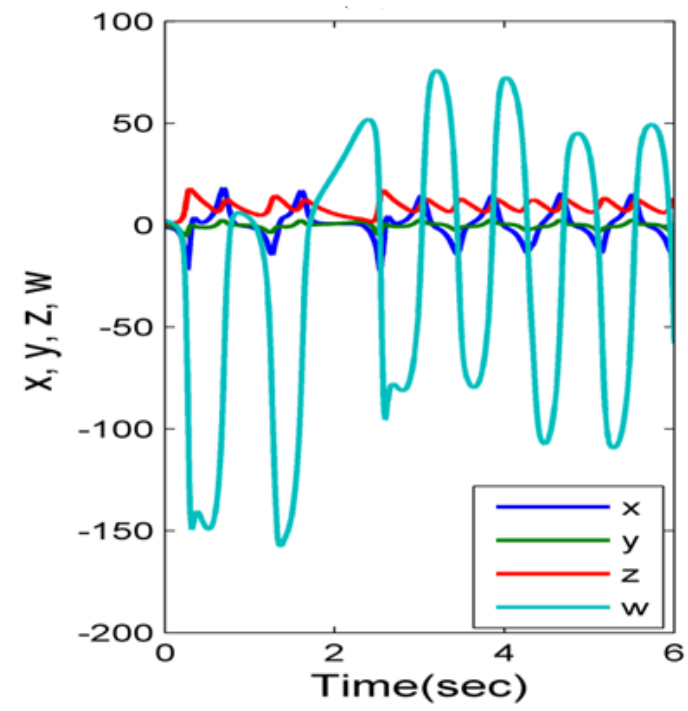

(a): Chaotic system

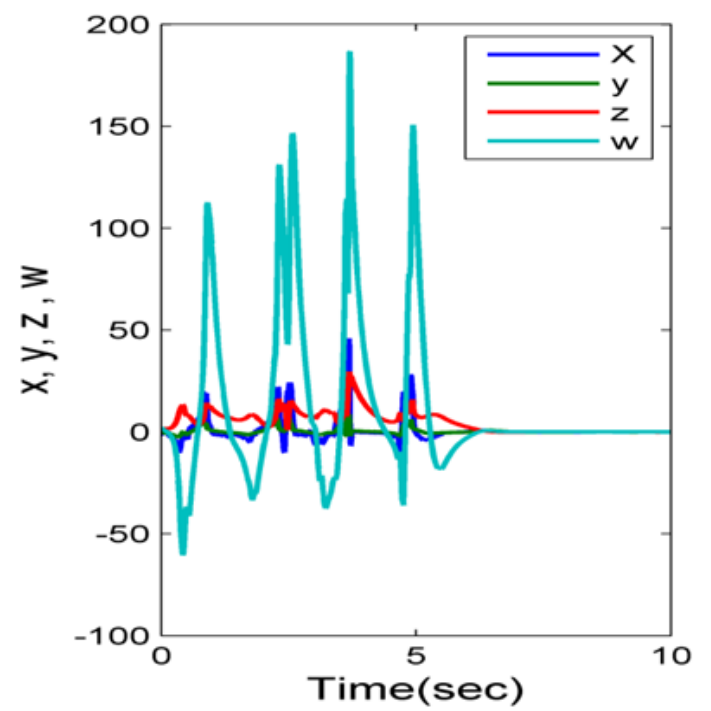

(b):After add unit control

Figure(4): Stabilization of system.

This method achieves the control of the system (1), because it satisfies all four condition of R. H. T. and all the eigenvalues that have been found negative, so that we can control the behavior of the system and made it stable. The proof has been completed.

\section{Conclusion}

In this paper we used the strategy of enhancing linear feedback control to solve 4D continuous hyperchaotic system. The basic properties depend mainly on Lyapunove exponents to analysis system is chaotic or stable. We depend on the result of eigenvalues we never use any strategies of linear feedback control on the system (1), because all of these strategies depend on adding one unit control on chaotic system remedy stable. Linear feedback control fail to control the system (1), except the method of enhancing linear feedback control because we will add two or more unit control on the chaotic system. Through the results obtained show that four ways to control the behavior of the system (1) and made it stable. 


\section{REFERENCES}

[1] Ahmed E. \& . El-Sayed A.M.A. \& El-Saka , H. A.A"On some Routh-Hurwitz conditions for fractional order differential equations and their applications in Lorenz, Rössler, Chua and Chen systems", Physics Letters A 358, pp. 1-4, .(2006).

[2] Ahmed, I. \& Mu, Ch.\& Zhang F. "A New Chaotic Attractor With Quadratic Exponential Nonlinear Term From Chen's Attractor", International Journal of Analysis and Applications Vol. 5, No. 1, pp.27-32, (2014).

[3] Aström, K. J. \&Murray, R. M. "Feedback Systems An Introduction for Scientists and Engineers" (2007).

[4] Aziz, Maysoon M. \& AL- Azzawi, Saad Fawzi ,"Some Problems of Feedback Control Strategies and It's Treatment", Canadian Center of Science and Education, Journal of Mathematics Research , Vol. 9, No. 1, pp. 39-49, (2017).

[5] Daltzis, A. P. \& Volos, K. Ch. \& Nistazakis, E. H. "Analysis, Synchronization and Circuit Design of a 4D Hyperchaotic Hyperjerk System", computational, MDPI., 6,14; DOI:10:3390/computation6010014, pp. 2-19, (2018). www.mdpi.com/journal/computation

[6] Emad , M. E. "Dynamics and synchronization of new hyperchaotic complex Lorenz system" , Mathematical and Computer Modeling Vol. 55 , pp. 19511962, (2012).

[7] khlef, I. \& Mansouri, N. "Hyperchaotification and Synchronization of Chaotic Systems", International Journal of Control Science and Engineering, Vol. 2, No. 4, pp. 69-74, (2012).

[8] Mehdi, S. A. \& Qasim, H. A. " Analysis of a New Hyper Chaotic System with six cross-product nonlinearities terms", American Journal of Engineering Research, Vol.6, No.5, pp.248-252, (2017).

[9] Pang, Sh. \& Liu, Y. "A new hyperchaotic system from the Lü system and its control", Journal of Computational and Applied Mathematics, pp.2775-2789, (2011).

[10] Vaidyanathan, S. "Adaptive Anti-Synchronization of 5-D Novel Hyperchaotic Systems and SPICE Implementation", DOI: 10.1109/ICCIC.2014.7238278, Vel Tech University, India, (2015). 